\title{
16. Ethical issue determination, normativity and contextual blindness: Epistemological studies of the limits of formalism in ethics and their consequences for the theory of governance
}

\author{
Philippe Goujon and Catherine Flick \\ Université de Namur, De Montfort University
}

\section{Information society, technical development and ethics}

The impact of techno-scientific developments on societal evolution and lifestyles no longer needs to be demonstrated. In particular, the last half of the twentieth century has witnessed a considerable acceleration of the integration of technological elements into the means of economic production and social life in general. The profound transformations that have taken place in the last few decades equally involve energy, transportation, construction, telecommunications, administration, medicine, pharmacy and agricultural sectors. These transformations are closely linked to techno-scientific developments and particularly to stunning developments in information and communications technologies (ICTs). The information society emerging in the contemporary period, however, can no longer simply be considered as a result of technical mutations. Up to now, this ongoing global phenomenon that is technological, economic, political and cultural, is in search of social and political projects, references and reaffirmed values. We are faced with the task of building networks that are based on a cultural model incorporating clear collective choices, so that the principles of democracy are transferred on line - hopefully without loss - in the future. The knowledge society is the embodiment of a change in civilisation whereby science and technology have become omnipresent and are developing at a disconcerting rate.

More and more people, in particular through their work and their responsibilities, are questioning the relationships between knowledge and power, between science, technology and society, and the notion of governance whereby decision- 
makers impact on the public. In this fast-changing context, the relationships between government and citizens, between industry and consumers, and between designers and end-users is no longer the same. New governance models must be established and socio-economic progress must be rethought, providing a stronger consideration of the sustainability issue. ${ }^{1}$ Consequently, different relationships and a positive dialogue between the scientific community, society, society's decision-makers and end-users are required, as underlined in the Council of the European Union Decision of 30 September 2002 (2002/835/EC). ${ }^{2}$ This document emphasises the need for 'structuring the European Research Area' (2002-06), adopting a specific program for research, technological development and demonstration: 'Today, and even more in the knowledgebased society of tomorrow, science and technology have a ubiquitous presence throughout the economy and in everyday life. If they are to realise their full potential in securing a continually increasing quality of life - in the broadest sense - for Europe's citizens, new relations and a more productive dialogue between the scientific community, industry, policy-makers and society at large, as well as scientists' critical thinking and responsiveness to societal concerns, will be needed.'(12)

The evolution of ICT is driving our society towards situations and applications where humans interact so deeply with 'intelligence', pervasively distributed among them, that, at some point, we will reach a divide where a fundamental choice will be presented to us: to develop a 'utopian' environment where all humans will have access to an empowering and accessible techno-environment ('ambient intelligence (AmI) environment') or head towards a 'dystopian' environment where Bentham's panopticon ${ }^{3}$ will become an increasing reality due to thousands of sensors, computers and networks that will track every human movement. David Lyon called this new form of 'cooperative surveillance', 'synopticon' and 'scopophilia' (1993; 2006). The notion goes beyond Bentham's panopticon and was interpreted by Zygmunt Bauman (1995) as a significant trend of the globalisation process.

In a world that is becoming increasingly homogenised, any capacity for questioning is likely to be stifled by the rational constraints extended to all

\footnotetext{
1 See, for example, European Commission (EC) (2002), Science and society: action plan, European Commission, Brussels.

2 Council of the European Union, Decision of 30 September 2002 adopting a specific program for research, technological development and demonstration: 'structuring the European Research Area' (2002-2006): (2002/835/EC). English version: <http://eur-lex.europa.eu/LexUriServ/LexUriServ.do?uri=OJ:L:2002:294:00 44:0059:en:pdf>

3 The famous Panopticon was designed by Jeremy Bentham, British jurist and philosopher, towards the end of the eighteenth century. It is a type of prison, also known as the 'Inspection House', which enables an observer to watch all the prisoners without their knowledge. This essential principle of construction is reflected in the Greek neologism, pan — meaning 'everything', and opticon — concerning 'vision' and, as such, the word is meant to express 'the all-seeing place'.
} 
fields. This brings us back to the question of the possibilities and the place of ethics within this framework of corrective regulation. The problem of the real action of norms in the context of technical development is crucial and curiously largely ignored, and needs to be scientifically taken into account if ethics is to be effectively integrated in technical development and more generally in the relationship between science and society. The need for serious attention to the problem of allowing the conditions for the development of a responsible information technology is strong. It is based on the conditions for developing what is sometimes referred to as value-sensitive design, which recognises that any technology and/or artefact (ie ICT) embeds values into the technological design, research and development. ${ }^{4}$ It assumes that human values, norms and moral considerations are imparted to the things we make and use and it construes information technology (and other technologies for that matter) as a formidable force which can be used to make the world a better place, especially when we take the trouble to reflect on the ethical aspects in advance. A wider approach in evaluating emerging technologies should include not just the legal dimension (often referred to in the ICT field as 'compliance') or the social acceptance, but also the ethical dimensions which imply a normative horizon that can't reduce itself to the mere social acceptation. ${ }^{5}$

\section{Conditions for a transformative critical room ${ }^{6}$}

What we propose is to review the state-of-the-art in respect of the ethical analysis of ICT developments. Practically, the main problem consists of the absence of background: the strong push for technology development too often obscures the need for ethical consideration before a technical project is funded, developed and deployed. Some efforts have begun to consider ethics and ICT in the AmI domain that adopt different approaches such as analysis from scenarios or 'ethical review' panels (set up after the project has started; eg MINAmi). These consist of 'ethical experts', who may come from a separate community:

4 It is highly problematic, however, in that there is no mechanism developed for the choosing of the relevant values: simply relying on the emergence of values once the technology or context is inspected (Friedman, Batya, Kahn, Jr, Peter H, \& Borning, Alan, 2006, Human-computer interaction and management information systems: Foundations, ME Sharpe). Value-sensitive design, then, relies on the identification of direct and indirect stakeholders, the benefits and harms for each (particularly looking at the different levels of competence for each group, for example, the elderly may not be so proficient with the use of technology). For that reason one shouldn't confuse value-sensitive design and ethics. A value-sensitive design approach does not by itself ensure that the values that will be embedded in the technical artefact are ethical values.

5 A society can, in fact, reach a consensus on something that is ethically unacceptable.

6 The concept of transformative critical room is from Crutzen (2003). These are characterised as those interaction worlds where actions of questioning and doubt are present, which have the potential to change habits and routines, where the 'change of change' has a differentiated potential.

7 MINami (Micro-Nano integrated platform for transverse ambient intelligence applications, an FP6 project). 
the 'technical' community is typically separated from the 'ethical' community. One of the reasons for this separation is the specialisation of high-level studying (eg, within universities) where the 'technical' study plan of engineers is different from that applied in 'humanities' subjects of other faculties.

An interdisciplinary approach is strongly required. ${ }^{9}$ Indeed, some technical universities in Europe are introducing areas of study such as 'Science, society and technology' for engineers, or 'Computer ethics' for computer scientists, but these courses are not always included as a mandatory component. Scientific projects can raise ethical questions, evidenced by the rules and procedures of the European Commission for the systematic ethical evaluation of projects submitted for funding in FP7 (Seventh Framework Programme). The elaboration of ethical standards, however, is made uneasy by the common dividing line which separates the justification of norms and their application. These two levels ought, however, to be integrated if one considers the issue of ethical universality, which has to be newly analysed within the context of a multicultural Europe (Drenth et al, 2006). The reflexive articulation of ethical norms and cultural contexts raises many problems, the first of which is the problem of the conditions of an ethical reflexivity. ${ }^{10}$

This is natural because the researchers and technical developers of ICT systems focus mostly on the technical and economic challenges before them, and are not usually aware of potential ethical issues because they see ethical considerations and analysis as an obstacle to the technical and economic development. In short, the problem we must first analyse is not so much the problem of determining solutions to ethical issues as to settle the conditions for raising ethical questions, and for a new approach that authorises a real reflexivity which allows for a questioning of the integration of ethics in complex technical systems. The obligations set out by economic constraints, interests concerned with the influence of experts, the general impression of the ineluctability of the technical projections, social requests, and the needs for the consumers make it increasingly difficult to define the conditions of a critical perspective respecting the moral autonomy requirements for thought.

8 For example, noted in the 'Human report ethical audit' produced in December 2004 (edited by P Goldie, SA Döring and WP10 members, <http://emotion-research.net/deliverables>. Humaine (Human-Machine Interaction Network on Emotions) was an IST FP6 project.

9 There is some recognition of the interdisciplinary problem, which has resulted in the PEACH project ('FP6 coordination action on presence') that includes a working group on social impact, legal issues and ethics. The approach taken is to analyse social impact scenarios and raise and address potential ethical issues $<$ http:// www.peachbit.org >

10 Reflexivity may be defined as the capacity of actors and institutions to revise basic normative orientations in response to the evolution of economic, techno-scientific or political systems and to shortcomings in current modes of regulation. This reflexivity is not given, however, and needs to be specifically integrated into governance approaches. 
We do not mean that existing criticisms don't allow for a certain reflexivity. We support, nevertheless, that these criticisms, generally, show a tendency to restrict ethics to a categorical field by sacrificing the existence and tension in the name of flattering pragmatism, being satisfied with ad hoc answers to artificially isolated specific contexts and being conditioned by the reigning instrumental rationality. An example of this would be the use of legal regulation or best practices documents that are decontextualised and not reliant on ethical principles, but which instead aim to avoid litigation or censure.

The danger and problem is to limit the debate to the scientific perspective alone (hence the importance of expertise, and the tendency among politicians to favour traditional, 'top-down' governance of activities in which risks are involved) and, shunning an approach based on technology assessment (TA), debate the meaning and the ethical, cultural and social stakes. Instead of initiating an inclusive debate on the nature of the different forms of knowledge and visions of the world, discussions limit the debate by adopting a positivist and, more often than not, reductionist approach that leads to cognitive closure, where those involved are unable to consider other potential issues, or to 'step outside the box'. Hence, we ask the question: how can we elicit the cognitive openingup required for a genuine reflexivity that would allow us, as Jean Ladrière (1984) puts it, to extract the existential and the political meaning from the objective meaning? How can we decompartmentalise ethical discourse and make it play a more important role in the joint construction of technologies? How can we transcend the neo-classical, technological approach (the cost-benefit approach for Slovic)?

The economists' answer appeals to the industrialists, for it confirms their practices and habits. Positivism has become so potent these days that the project of emancipation through reason is, for the most part, either rejected or ignored. In its place appear instructions on how to increase one's power over social processes that have been reduced to the status of objects. Hence again - even if, as Ulrich Beck has stressed, this is a perspective that needs qualifying there is significant difficulty in controlling the rampant growth of technological innovations politically. More often than not, political institutions make do with a regulatory and financial framework within a dynamic system accompanied by positive feedback that leads to a self-fulfilling positive feedback loop.

In this context, expertise, be it philosophical or scientific, becomes the indisputable new source of normativity, ${ }^{11}$ and the problems revealed are confined to a scientific perspective alone - which means that the problems taken into

11 Normative is contrasted with its antonym, positive, when describing types of theories, beliefs, or statements. A positive statement is a falsifiable statement that attempts to describe ontology. A normative statement, on the other hand, is a statement regarding how things should or ought to be. Such statements are impossible to prove or disprove, thus forever banishing them from the world of the scientific. 
account are confined to the realm of strict scientific rationality, and democracy is confiscated. One must be wary of any theory which tries to objectify the world we experience (emotion or attitude, as in the MIAUCE ${ }^{12}$ project - Multi modal Interaction Analysis and exploration of Users within a Controlled Environment) in order to predetermine the form of the world we share. There's a risk that the possibility of genuine reflexivity will be stifled by a technological and scientific rationality imposing its value system with, as a result, a dismissal of the prestige of moral reason.

This dismissal of the prestige of moral reason found credit in 'progress' of all kinds that were acquired from scientific work and technological discoveries. This progress, tested only slightly in many fields, maintained the idea (or the myth) of a possible emancipation with regard to morals. Modern thought, thus, by no means needs morals, since it is, in itself, an action, basing humans in knowledge and technical rationality.

What is at stake is of importance, indeed various sectoral ethics tend increasingly to reinforce social differentiation characteristics of modernity by proposing an internal, and specific, framing of moral problems, with the risk of exclusion of other external and alternative framings. As a consequence, ethics is disconnected from the design of technological devices and the lack of a concrete grid of assessment concerning the embedding of ethics in technological development makes this issue important. Briefly, this is the European situation: some ICT projects investigate ethical aspects, but ethical considerations are not a 'matter of course' in the development cycle. In some cases, ethical experts are brought in at some stage in the project to assess the ethical implications. As a result ethics is often an 'add-on', a sort of accessory and instrumentalised guarantee, and not properly integrated nor understood in its methods and objectives, which are clearly very different from the method and objectives of sciences and techniques.

Consequently, there is a need for the inclusion of ethical consideration before, during and at the end of technical and scientific projects, so that the technology 'incorporates' and tackles the ethical side (within its whole concept and implementation). The risk is that by not analysing the conditions (institutional, rules, cognitive) for the effective integration of those considerations in the context of a technical project, the ethical considerations will be excluded from the technical rationale and treated as a totally separate domain. The consequence of this separation is a loss of impact, and an undermining of the integral role of ethics in the application of technology. This is understandable since the technology can only be limited to the set of its rules (that is, objectivity, and the technical rationality which frames its vision and conception).

12 MIAUCE is a European Commission FP6 project. 
Ethics is never in the answer (always conditioned) but well into this dynamic movement of questioning, before the action and on a border, which separates our subjective existence (with its presuppositions, preferences, convictions and hidden motivations) from the constraining externality (economic constraint: political, hierarchical, technical, and ideological). The ability to position ourselves with a moral freedom is fundamental, as we are then able to question ethical feasibility and conditions.

These issues are at the basis of this problem if we desire to take into account the fundamental changes that affect our world.

\section{A world in the midst of change}

What is at stake at a time of globalisation and the expansion and domination of technology, market forces and calculating rationality, is the capacity of societies to regulate themselves. It is also the possibility of taking a reflexive relationship into account in the emergence of collective action based on individual behaviour in institutions of self-regulation.

The feeling that there is something automatic about the growth of technology and economic and administrative rationalities is all the more widespread since their political origins are masked, reinforcing the impression that the prospect of democratic supervision of social sub-systems - the possibility, that is, of collective autonomy in the conditions of a radicalised modernity aimed at dominating nature and mankind - is barely credible, if not to say irrational.

Yet, the growing desire shown by citizens today to be involved in a certain number of decision-making mechanisms is tangible. This is notably the case with regard to situations perceived as presenting risks: people are loath to run risks that they have not been warned about beforehand, that they have not accepted or that have not been debated in a democratic manner. The questions this raises extend well beyond the field of science and technology and are essentially bound up with political and ethical issues, as well as with technological, economic and financial stakes. It has to be accepted that, in order to face these challenges and the risks and dangers attendant upon the spectacular growth of the technosciences, we need to rethink our modes of governance in science and technology.

Arguments involving a semantics of risk or danger are commonplace in modern societies and now dominate discussions of governance. Though the risks that might be mentioned are heterogeneous in nature (bio-technological risks, epidemiological risks, or challenges relating to geopolitical security), a number of common features can be identified. The scale of each risk is virtually global, both in terms of the threat itself and of the solutions which might be envisaged. 
Each involves complex phenomena, funds of knowledge that are in conflict with one another, developments in science and technology and substantial public funding if the challenge is to be met; each presents potentially gigantic mortal dangers and, above all, involves much public debate about current assessments of the risks involved. These risks pose challenges in the realms of politics and governance. To understand them is essential, all the more so since supervision of the norm is no longer limited to vertical, state-type supervision alone but today passes through far more diversified and complex channels. These questions relating to the role of governance in a context that is uncertain and involves risks cannot seriously be addressed, therefore, without posing the question of normativity and of the links between society, norm and law.

\section{Social complexity and judicial norm}

Today, the State has de facto forfeited its monopoly on social regulation and the production of judicial norms. Faced with the problem of regulation and social order in a society characterised by the multiplication of sources of normativity, the failure of policies designed to reinforce the means available to the welfare state and the failure of deregulation, Jurgen Habermas $(1992 ; 1997)$ and Günther Teubner (1995) have each put forward a solution: self-regulation for the former, proceduralisation for the latter.

Both take as their starting point the difficulty of achieving collective autonomy in a modernity radicalised in its project of dominating nature and mankind. Social subsystems must be integrated by 'proceduralisation'. This means that the law should identify itself with what Teubner calls the 'structural judicial preconditions for a self-regulating society' (1995: 89). Similarly, Habermas favours a process-based model of law and, in so doing, means to give a new legitimacy to the legal system.

If one takes as given the functional differentiation of society and the multiplication of subsystems, each employing its own rationality and each running the risk of closing in on itself, the question arises not only of communication between these subsystems, but of where the legal system stands in relation to them. As Teubner sees it, 'the law cannot monopolise the epistemological authority pertaining to other forms of knowledge and alone assume full responsibility for all the constructions of reality. ... It cannot, however, delegate all epistemic authority to the other forms of social discourse,' (1995: 202) with the attendant risk of conflicts emerging between these different systems.

Faced with conflicts of this kind, there is a very real danger that, in many instances, positivism will end up presenting itself, in cultural terms, as the only genuine form of knowledge, the only activity endowed with meaning, and will 
forgo, as Habermas has remarked, 'any reflection on the role it plays in the social context, that of a legitimation of technocratic domination or of vested interests ${ }^{\prime 3}$ (Gentil, 1997). The activity of the state is no longer geared to achieving practical ends, but to finding technical solutions to crises affecting the system. Hence the growing importance of experts and the depoliticisation of civil society. Hence, also, the force of technocratic ideology, an unacknowledged domination that arises from the fact that it hides behind technological rationality. The risk approach can, in many cases, be a strategy to divine more profound issues.

\section{The limits of the risk assessment approaches}

The perception of risk cannot be disassociated from a type of informal assessment of technology which combines socio-economic and ethical stakes and the question of the relationship (whose relationship?) to institutions. In the absence of certainty, precaution means coming down on the side of procedural strictness. When the 'truth' of a situation and the 'reality' of a risk cannot be established, it is the strictness of procedures, and of the actors involved in drawing up, implementing and overseeing those procedures, which becomes the dominant value. The absence of certainty does not prevent us from analysing and managing a situation strictly.

To limit the debate to the question of risk alone, regardless of the problems relating to risk assessment, has an important consequence: when all is said and done, it limits the debate to the scientific perspective alone (hence the importance of expertise, and the tendency among politicians to favour traditional, 'topdown' governance of activities in which risks are involved) and, in shunning an approach based on TA, shuns a debate on the meaning and the ethical, cultural and social stakes of biotechnology and genetic engineering in the case of genetically modified organism (GMOs) or on the representation of ICT. Instead of initiating an inclusive debate on the nature of the different forms of knowledge and vision of world, discussions limit the debate by adopting a positivist and, more often than not, reductionist approach that leads to cognitive closure, even if the framework is masked by an appearance of deliberative democracy the implementations of which (particularly citizens' conferences), disconnected from decision-making bodies, serve only to mask traditional forms of governance 'from the top down'.

13 J Rivelaygue, Leçons de métaphysique allemande, Vol. II / Kant, Heidegger, Habermas, p 459, quoted in Gentil (1997). 


\section{The autonomy of the technique in question and the legitimacy of ethics}

It is undeniable that 'the scientific method', as a considered and self-checking specification of the rational method, is at the base of the common dynamics which crosses the properly scientific field as well as the technological field. What this dynamics tends to generate, is an autonomous reality, an intermediary between nature and properly human reality, a kind of 'third world', of which the formal structure is given in conceptual architectures of science and the concrete figure in the equipment of all kinds which constitute around us, the extremely dense network of what one calls the technical world. Nevertheless, if there is autonomy of the technical sphere, this autonomy is, however, only an expression of an ideology, that of the engineer, or a society which justifies, by subjecting its various components to scientific and technical rationalities, its incapacities to find political and social remedies for its problems. In a world full of doubt, characterised by its complexity, the technique becomes, or tends to becoming, in spite of the undeniable suspicion which weighs on it, the supreme reference of the truth and the pragmatico-economic effectiveness. The myth of progress, after having been identified with science, coincides with the technique, accompanied with a decline of the question of the truth in the name of a pragmatism which is more than ready to respond to all the economic and industrial requirements of the context.

In this arena, ethics is reduced to playing the role of mere justification and legitimisation of what was a priori decided on according to economic, technical and industrial justifications, without being able to exercise its normative specificities and characteristics. This is a consequence of the fact that, conditioned by the technical framing, we have forgotten that technology is not neutral. It is a manner of thinking, of making, and of transforming the world which cannot be disassociated from policy or subjacent choices of ethics. From this point of view, data processing and ICTs are not neutral and reflect, in their constitution and their use, expectations of the society and are influenced by their socioeconomic context. For example, technological innovations that focus on satisfying needs of individuals also come to fulfil a function dependent on the cultural features of the society in which they fit. As in any society, these needs can be seen as negative or positive, for instance, perhaps negatively to control, or more positively to align the political, social and institutional goals with the individuals' desires (Lyon, 1993). On this view, the organisational life has to become increasingly rationalised and controlled and organisational control will be 'less and less apparent and increasingly powerful' ( $\mathrm{H}$ Isaac and Mr Kalika, 2001; WJ Orlikowski, 1991; JR Barker, 1993). 
These characteristics also apply in a broader social sense, with the result that the introduction of ICT also shapes social practice: 'information technology has become a constitutive technology and partly constitutes the things to which it is applied. It shapes our discourses, practices, institutions and experiences in important ways' (van den Hoven, 2007: 68).

\section{Non-neutrality of ICT and Aml}

This recognition of the non-neutrality of ICT should not be surprising, after all, technology is designed with a purpose guiding the technical direction. The implications of the technology, however, in its capacity to affect and change social practices are not so easily seen. The context in which the development takes place - the culture, language, discourse - already provides the framework for the resulting artefact. Consequently, although an expert in another field (eg ethics) can advise on possible impact, the advice is reinterpreted within the context and cultural knowledge of the development team, and thus does not extend the understanding to a wider view. That is, 'learning' has not taken place. Without this deeper understanding brought about through learning, we are all bound in some way to narrow horizons that need an external mechanism to be opened to wider horizons. In the case of ICT and AmI, more generally, the construction of the social legitimacy (and not just acceptability) of science and technology requires that the subjacent metaprinciples of normative nature be considered along with techno-scientific actions. The technological artefact forms the system and is also a form of organisation and perpetuation of social reports, which are a manifestation of the dominant ways of thinking and behaviours. The technological artefact is always an historical and social project, and this project reflects the intentions which nourish a society, the interests which dominate it and the values which guide it.

Technological progress in all these fields has contributed to the shaping of the AmI vision, but at the same time, progress in the diffusion and acceptance of past and current ICTs was mutually important. In 10 years, GSM has grown in Europe to more than 300 million subscribers. In many European countries, penetration rates of mobile phones are above $70 \%$ of households. And SMS has given a considerably boost to the mobile services market during the last years. Internet access from home has increased in the EU15 to 40\% in June 2002 (against 28\% in October 2000) (Eurobarometer 2002). If the increased diffusion and usage of computers, the Internet, mobile phones, etc. had not happened, technological progress in these fields would have slowed down. And acceptance of these technologies is enabled by demographic and social 
trends such as the emergence of individualism, diversity, mobility, and choice of personal life styles, affecting the structure of groups and community and the ways we live and work. (Punie 2003, 17)

In the case of the vision of AmI, at first glance it seems that it is based on technological progress in the fields of microelectronics, communication networks and interfaces. Nevertheless, it is also driven by socio-economic factors that go beyond the technologies alone, including but not limited to economic neoliberal rationality, rationalisation of the production, demographic conditions, impact of terrorism, and consumerisation of communication.

\section{For a critical perspective}

As we have underlined, every technological artefact is a construction which rests on some a priori foundation (social, political or economic) and, even if it is partially suggested by preliminary information on the behaviour of the objects, it reinterprets the latter starting from its own categories. The political impact of a technological artefact cannot thus be assigned to this artefact alone, but must be allotted to the techno-speeches which diffuse it, give it a specific meaning and envisage for it specific usages. Data processing and innovations related to ICT, if they seem to be binding to individuals, come, actually, to satisfy a need and to fulfil a function largely dependant on the cultural features of the society in which they fit.

It is only to the condition of recognising the non-neutrality of ICT that one can start to change its cognitive framing and consider ethical and societal issues. Without this propaedeutic step, one can just interpret the world and technology within the restricted cognitive fields allowed by its framing (in our case the technological framing). The result of this is to either negate any justification of ethical and societal considerations or to instrumentalise them and consider them as a means to obtain a sort of ethical guarantee and label. This latter issue is a problem with all ethical guidelines: they don't take into account the issue of their application, and so, most of the time they have no effect at all. The mechanism which consists of providing the answer expected by a given context (such as economic or industrial contexts) poses ethical questions since the justified context itself becomes the justification of the social function of ethics.

This recognition of the non-neutrality of ICT nevertheless returns a realistic ambition of relativising instrumental rationality and aiming at political and societal control, which means also its rehabilitation into the world of social and cultural life. The immediately urgent issue is to correct the manner of approaching ICTs aiming at applying approaches which dissociate the social approaches from the technological ones, and political approaches from economic 
and ethical. Too often the accepted responses are only the economic, political and institutional constraints. It is undeniable, for example, that policy-makers are fascinated by technology. Positivism continues to influence our political leaders, who are in a state of utter disarray in relation to the complexity of our world. A symptom of this tendency is the call to use technology in all areas of public policy - education, health, environment, administration - to solve the problems which affect our society, and afterwards use an appeal to ethics to justify the decisions that were already taken (for example, the European ethical assessment of technical projects).

Thus we need to recognise that the possibility of a critical perspective doesn't mean we can ensure its reality, and indeed many factors can prevent the effectiveness of its realisation.

\section{Ethics in trouble}

We must acknowledge here that the background we use, and build on, refers to the contextual pragmatics and the theory of governance developed by the Louvain school, ${ }^{14}$ as it offers a solid, theoretically founded framework which ensures the above requirements. This theory relies particularly on opening up the process to many stakeholders, who reflect and assess the ongoing feasibility for the governance tools used throughout the full lifetime of the project in order to ensure efficiency. The justification for relying on this theory is that it directly addresses the problem of the conditions for the effectiveness of norm expression. It does this from a theoretical perspective and using an applied set of studies.

As it is currently, ethics is restricted to a categorical field by a pragmatic use of ad hoc answers to artificially isolated contexts which are conditioned by the reigning instrumental rationality. Deontological codes and ethical guidelines are good examples of this because they relate to issues that are, most of the time, sectorially defined with a theoretical approach that is chosen by 'experts' employing a decisionist process (which refer to an a priori chosen principle, with their own specific framing, determined by their field of expertise. This sectorial ethics reinforces the social differentiation characteristics of modernity by proposing both internal and specific framings for moral problems. The risk, here, is that the possibility of genuine reflexivity will be stifled by a technological and scientific rationality imposing its value system. Sectorial ethics tends to also propose an internal and specific framing for moral problems, risking the exclusion of other alternative framings. For example, in ICT particularly, developers will solve problems using technological means (such as websites

14 For more details, refer to Lenoble \& Maesschalck (2003; 2006); Coppens \& Lenoble (2000); Maesschalck (2001). 
offering privacy controls) rather than questioning whether the technology should raise such problems in the first place (exclusion of social or cultural framings).

In this context, expertise, be it philosophical, scientific or economic, becomes the indisputable source of normativity, and the problems revealed are confined to these expert perspectives alone. As a result, ethics is often an accessory without proper integration nor understanding of and respect for its methods and objectives, which are very different from the methods and objectives of the science or technological development.

Consequently, there is a strong need to investigate and reflect on the governance conditions that allow for an ethical reflexivity inside the project and for the effectiveness of that reflexivity, so that ethics does not reduce itself to a means to satisfy the conditioning constraints of the context, such as economic, political, or scientific constraints. If reduced as such, it transforms the question of the ethical acceptability into the question of the social acceptance of the technology, which is easily addressed by sociological enquiry. Such governance conditions also need to allow for the inclusion of ethical consideration before, during, and at the end of technological and scientific projects. This is so that the technology incorporates and is confronted with the ethical side throughout its conception, development, and implementation stages.

Within a regulation framework, for ethical integration to be successful, it firstly needs to be considered for inclusion in that framework, and to be accorded a certain status which acknowledges and respects its fundamental epistemological and methodological characteristics and requirements. ${ }^{15}$ For this we need to consider the cognitive structures, the stock of knowledge, the habitus, based on

15 Agreeing with Ladrière, 'The ethical dimension [...] manifests itself when it exercises and founds an authority under an unconditional and, in a certain way, intemporal form. Speaking of a historicity of ethics introduces different variations and relativity' (translation by the authors). Nevertheless, as Ladrière recognises, there exists a historicity of ethics and that, for a very simple reason, is related to the fact that historicity is a fundamental constitutive dimension of the existence in the meaning where it can't be reduced to a mere contingent proprietary but, on the contrary, must be understood as a structural requirement. Ladrière, in this, drew from the lessons of contemporary phenomenology, according to which, the historicity is a dimension of the existence of the dimension underlying the historical consciousness by which it is left as a historical form. Ethics, itself a constitutive dimension of the existence, is necessarily affected by this other constitutive dimension which is the historicity specific to the human condition. As a result, the ethical dimension must necessarily inscribe itself in the historic effectiveness; it cannot deploy itself concretely in the 'historic flesh'. There is no ethical effort that does not model itself on the historical effort. But to this reverberation of the historicity on ethics, and to this historicity of ethics, should be added, according to Ladrière, an 'ethicity' of the historical, that is to say, an ethical determination of the historicity (understanding essentially as the projection into the effective real history of the ethical dimension). If there is a historical determination of ethics (historicity of ethics: the first level of this comes from the fact that ethics evolved, and the second that it acquires its effectiveness only through the historical forms that it takes; this explains why the ethical field is an open, not closed, field), there is also, reciprocally, an ethical determination of historicity (ethicity of the historic). Such a crossing constitutes what Ladrière called 'the dual relation'. J Ladrière, 'Philosophie politique et philosophie analytique', in Ladrière \& Van Parijs (1984: 222). 
our background, which founds our relation to the world. The background, or the 'stock of knowledge' (from the Husserlian analysis), gained from the analysis of the experience, is a corpus of preliminary knowledge and is necessary for the act of interpreting the world.

In this context, the 'stock of knowledge' takes the form of an individual's interpretation schemata (after Kant (1964)) or the cultural inheritance (according to Alfred Schütz (1943, 1951, 1954, 1959)). The concept of 'stock of knowledge' can be defined as a concept whose meaning is broader than the concept of the 'reserve of experience'. It gives an account of the preliminary knowledge that is also from social origins. The stock of knowledge of the socialised individual has a basis of knowledge that is composed of three parts: lived experiences, common knowledge (traditional or scientific knowledge), and knowledge related to corporality, skills, and other practical things. The processing of the stock of knowledge as preliminary knowledge (foreknowledge) is used in theories of interpretation. It is not difficult to see a parallel between the cultural knowledge in Schütz's (1951; 1954; 1959) conception and the Gadamerian (1976) conception of prejudices. After the rehabilitation of the prejudice, the former receives an important function in understanding practice, and becomes one of the fundamental elements of the hermeneutic circle. ${ }^{16}$ The interpretation practice always begins (according to Gadamer) from a preliminary knowledge. Concerning the action, to quote Ladrière (1993), 'the action mobilises itself, always under the inspiration, be it tacit or not, of an informing interpretation'. The action inscribes itself concretely in a class of events which anticipates and which is conditioned by its comprehension of the insertion process within its context. This understanding rests on a background that refers to the principles and presuppositions, related either to a community, or, for example, more globally to the dominating value of the society. The prejudice or the preliminary knowledge allows us to go within the circle of interpretation. From our perspective, it's precisely the a priori frame of contextualisation of practical meaning in reference to the actual possibility that needs to be destabilised, so as to allow the opening of the cognitive closure resulting from the framing effect.

To talk about background here is not an unnecessary detour. Through exploring these concepts, the normative discourse can be confronted by practical logic that may neutralise, by practical anticipation, the normative production's sought consequences. We can also conceive of the possibility of an internal distancing of the value systems that block all possibility of alternative understandings and all possibility of discussion of common norms (again, the framing effect). It

16 According to Spinoza, in order to understand extremely dense written material, one needs to keep in mind the historical background as well as the person who wrote it (that is, their history, attitudes, culture, outlooks, and bias). In order to understand the parts of the text, one must understand the whole, but the whole can only be fully understood based on the parts. The hermeneutic circle is the moving back and forth between these contexts, between the whole of the text and its parts (Ramberg \& Gjesdal, 2005). 
allows us ultimately to think about opening the closed cognitive doors, and to think about the access to the contextuality of the normative production. Marc Maesschalck (1998) writes that

the contextual efficiency has a meaning only within the strategic plan as information on the appropriateness of the mean or movement. Concerning the justification of the action, it has an effective relation only to itself on the model of a hermeneutics of the strategic judgement of application. We lose from that fact all possibilities of an immediate reference to the specific coherence of the context as an environment of the practical application of normativity if not as an environment that configures the relation to the norm in general. (1998)

The urgency is also not to limit ethics to questions of the institution and the decontextualised (or a priori contextualisation referring to a predetermined context) application of the standards and principles. Indeed, such an ethics is purely a decisionist one. Its reference immediately limits the problem of the adequacy of the ethical representation to the context of action and also ignores the origin and legitimacy of this representation - a practical way to automatically justify it and instrumentalise all ethical considerations and, also, to reduce the complexity of the context. This problem is all the more important from an ethical point of view, because the theoretical image of humans conveyed by a sphere of activity deserves, as underlined by Maesschalck, 'to be questioned according to its effective impact on the culture and the traditions. The extrapolation of a model of activity can become totalitarian when it claims to redefine the relation of a human with its horizons'. The function of knowledge in modern sciences is, in an increasing way, conceived in relation to the system of work. These sciences generalise and rationalise the technical capacity of humans on the objectified processes of nature and society, with the use of techniques of administration increasingly more effective and generalised.

Once the knowledge is reduced to the applied science, this type of science and rationality monopolises the rational behaviour. The positivist conscience, consequently, dogmatically combats any theory referring to the practice differently from those improving the possibilities of the practical applications. That means that the practical (moral) questions become the object of a decision and are confined to the irrational field, unless they are not, in their turn, subjected to the only technical criteria of instrumental rationality. This results in 'blocking any possibility of discussion on common ethical standards while imposing, preliminary a manner of understanding the world in general, a meaning of life determined usually inextricably by traditions, solidarity and personal identifications'. The explanation is that the directives required by the action are divided into a rational determination of techniques and strategies and into an irrational choice of systems of values. 
The consequence, for the economy governing the choice of the means, is a total freedom characterised by a 'decisionnism' in the choice of the highest goals (values associated with the action). However, as Ladrière underlines it, recalled by Maesschalck,

the decisionism is radically insufficient, because one cannot be satisfied to seek and pose principles of action and from that justify the action. It is also a question of permanently assessing the 'ethicity' of the lived situations, i.e. of their particular relationship with the ethical requirements, themselves included/understood ideally like realisation of the human one.

It is the fundamental reason why what is ethically at stake is not so much to find an answer but to make room for ethical thinking, that is to say an attitude that can localise the issues raised by technology and have a theoretical tool with which to face them. Without that ethical standing relying on ethical references, any answers are useless since the cognitive tools to understand and apply them are not present (the cognitive framing being in that situation still the technical framing). The ethical step cannot be limited to provide the elements to establish the justification of a decision. The ethical interrogation refers to the construction of a human order and questions the way humans are perceived and treated, ${ }^{17} \mathrm{a}$ construction that is most of the time absent from the TA process.

17 Ethics concerns convictions that are not explained in a logic of compromise. A consensus can respect the interests of all the parts in question without being, by its object or its purposes (industrial, economic, scientific), in conformity with the ethical requirements. The ethical provision precedes the consensual effort and is its only guarantee. But this provision is not obtained by negotiation, it refers to the intentionality of the actors, their relation to the real world, their conceptions of existence and on which values those conceptions are founded. Without such an image of human responsibility in relation to a real world, the stake of the ethical reflexion disappears. In the field of subjectivity, the ethical interrogation is not satisfied by transformation of the individual forces into social autonomy. It seeks to exceed the responsibility concerning the measurable to open a reflexion concerning the responsibility with regard to the non-measurable; that is, with regard to the destiny of humanity, life, and our world. If we think that it is impossible for us to measure what we are and to measure what is life, a particular dimension of our responsibility must also concern the irreducible dimensions of the subjects, of life, dimensions which are not calculable. Compared to the life given, ethics is a concrete answer where a figure of humanity with its specific features is at stake. It thus answers partially in the concrete world to the challenges of a future for the human world. It cannot elude the specific fields of activities. Ethics answer the injunction of reality when it questions the rational choices for the management of the limits of our capacity to answer. It refers the human action to a destiny which exceeds it, that of the life which is 'carried out' in it. Ethics must assumes a normative authority which wants to be free of any contextual constraints, otherwise ethics would be subject to the reign of instrumental rationality, and would transforms itself in its justification for objectives that are not ethically founded but may be, for example, economically driven. Refusing to be subject to such constraints we assume, in this chapter, deliberatively the normative authority of ethics. 


\section{TA expertise and ethics}

All forms of TA processes involve an expert committee designed to give input on the potential impacts of the technology. Many of the more modern forms of TA have stakeholder input, using one or more of many tools available to gauge the concern of users, shareholders and interest groups. The inclusion of participants from outside the expert community and from the groups that are likely to be affected by the technology is important for not only the identification of norms, but the construction of the contexts within which the technology will function. The norms, however, constructed by both the experts and the stakeholder participants are in no way required to be ethical norms and, in fact, they are most likely to be societal norms and expectations of the target groups. Of course some of these may correspond to ethical norms, but there is no definite requirement within TA for the explicit establishment of normative ethical horizons.

The ethical approaches that are used in TA depend greatly on the context, though it is safe to say that ethical approaches are not usually appealed to as such, yet some are underlying the motives for carrying out the TA. Consequentialism features highly in traditional TA, such as those identified in 1980 by Joseph F Coates: ${ }^{18}$ 'TTechnology assessment] emphasises those consequences that are unintended, indirect, or delayed', or by Marvin Cetron and Lawrence Connor in 1972: ${ }^{19}$ 'Technology assessment is an attempt to establish an early warning system to detect, control, and direct technological changes and developments so as to maximise the public good while minimising the public risks'. Later on, however, more deontological approaches were underlying the ideas for incorporation of the public and other interest groups in the discussions regarding technology and the potential impacts of it on society. Normative TA processes involve a particular focus on assessing technology against moral principles such as beneficence, respect for autonomy, justice, and harm prevention (Verbeek, 2006). A virtue ethics-based approach is rarely found in TA (however implicit), because it relies on assessment of the processes and practices involved in directing technology rather than the technology itself.

In terms of reflexivity, TA processes rarely involve any such reflexivity within their own procedures. With each type of TA comes a structured approach that is followed and includes the choosing of stakeholders and experts and methods of conducting focus groups. TA could, however, be used as part of a reflexion process within a project, allowing for a learning operation to take place and

18 Joseph F Coates, 'Technology assessment: here today, gone tomorrow', in Technological forecasting \& social change 49, 1995, pp 321-23.

19 Marvin J Cetron \& Lawrence W Connor, 1972, 'A method for planning and assessing technologyagainst relevant national goals in developing countries', in Marvin J Cetron, Bodo Bartocha, The methodology of technology assessment, Gordon and Breach Science Publishers, New York, 1972. 
then the project to adapt to the findings of the reflexion, and to determine the conditions for effective integration of norms into the technology being developed. Real-time TA does attempt to integrate some sort of reflexivity into its approach, by assessing the technology throughout its lifespan of design and implementation, but this is limited by the primitive nature of early technology and the problem of choice of stakeholders. These limitations restrict TA to being a tool to incorporate into an overall reflexive approach on a larger view of the technology and its ethical impact on society, rather than for it to be used as the point of reflexivity.

\section{From contextual blindness to ethical governance}

Ethics is in the position of questioning before an effective action, and is on the border that separates our subjective existence from constraining externality. Paul Ricoeur defines ethics as 'the aim of a good life with and for the other, in just institutions' (1990: 202). It is a teleological conceptual framework, therefore, with the aim for a social, collective, just way of living together in a 'good life'. In the cultural realm, ethics can be perceived as a legitimisation process of this pluralism of conceptions of 'good life'. There is a diversity of ethical demands that reflects an autonomisation of the action spheres in the social life and individuality sphere. These ethical responses to these demands align themselves according to the professional, social, and cultural contexts in which they are formulated and used.

There are a number of philosophical responses to the conception of ethics: ${ }^{20}$

1. Analytical: ethics is conceived as a theory of principles from which a preferable interaction can be formed (Rawls). It responds to deontological preoccupations.

2. Pragmatic: ethics is related to consensual procedures that allow the institution of common norms and their collective control (Habermas), related to the choices of society and of ethical decisions in conflicting contexts.

3. Contextualist: ethics is a way to rationalise the values of a culture (Charles Taylor), and allows formalisation of the normative pretention contained in cultural opinions.

20 As quoted by Maesschalck, 'The last book of Enrique Dussel proposes an analytical landscape of the main tendencies of contemporary ethics and questions their negative relation to the material dimension of values.' (E Dussel, 1998, Ética de la liberación en la edad de la globalización y de la exclusion, (Maesschalck, 2001). 
4. Semantico-symbolic: ethics is a disposition to respond to the absolution of freedom in relative acts (Ricoeur, 1990), and is directly related to the subjective aspiration for the respect for human life.

So, contemporary ethics keeps its diversity, but the diversity of tendencies hides some of the specificity and the consequences of such specificity. For example, analytical ethics (Rawls) and pragmatics ethics (Habermas) postulates a semantic indetermination. Semantic ethics (Ricoeur) finds that the legitimisation process of the norm doesn't belong to ethics, but that the real ethical question is the response to the injunction of the suffering of others. Contextualist ethics (Taylor) proposes a realistic ethics of the way that the subject assumes its cultural space.

The semantico-symbolic approach appears to be a connection between ethical efforts and life in itself, with the openness of the structure constitutive of the subjection to the injunction of historical reality. The problem is, however, that the actor needs to voluntarily submit itself to ethics: ethics' main challenge is this confrontation of irrational human behaviour with rational choices for the management of this behaviour.

Thus, if ethics is to assert a normative authority, which is a fundamental characteristic of ethics, since ethics concerns the relationship between what is and what should be, it is necessary to question the condition for its effective integration in the context of technical projects. The conditions for effective integration relate directly to the normative conditions, that is, the relationship between the norm and the context. Once knowledge is reduced to the rational field, limited to sciences and applied sciences, the practical questions are perceived as belonging to a different realm, which is seen as not having the same properties as the scientific and technical realm, and become the object of a decision. They are then confined to the irrational field, unless they are subjected to the only technical criteria of instrumental rationality. This decisionism is radically insufficient, since one cannot be satisfied (as often occurs within deontological and expert approaches) to choose and pose principles of action and, from those, justify the action (that will in return justify the principles). Here we find ourselves in a circular argument that is clearly unfalsifiable, because the result is justified by the principle, and the principle is legitimised by the result. The ethical step cannot be limited to provide the elements to establish the justification of a decision, since ethics must assume a normative authority, free of any contextual constraints. By this we mean that it is not the norm that is free of any contextual constraints, but the relationship that the individual has with the norm. If it is not, it is simply subject to the rules of instrumental rationality, and becomes a justification for objectives that are not ethically founded but are, for example, economically, politically, or scientifically driven instead. 
In general there is a fragmentation of practices due to these ad hoc sectorial responses to artificially isolated specific contexts. This fragmentation is generally dealt with by inflating ethical approaches and responses (for example, deontological codes, ethical guidelines and ethical charts). The mechanisms that give responses expected by these specific contexts are not questioned, since the justified context becomes itself the justification of the social function of ethics.

The classical deontological, consequentialist and utilitarian ethical theories are in trouble: they talk about values without having contextualised these values (suspending this contextualisation), with the context later appearing mysteriously (and conveniently). This lack of foundation of the context means that it escapes the rationalisation proposed by ethical theory.

\section{Proceduralism}

What about proceduralism (as a philosophical approach, and not as a political method)? The option of proceduralism is generally taken to be a solution to the problem of the contextual limits of the other ethical theories. Indeed, it appears as a sort of synthetic combination of requirements that are usually separate among the two competing traditions of moral philosophy, the deontological and the teleological, in the broad sense of the word. If one takes the example of Habermas' discourse ethics and, especially, the principles of discussion and of universalisation (Principle D and Principle U) (1981: 81-2; 145-46), it is undeniably an original procedural combination of requirements. It combines criteria that are both deontological (criteria of universality and obligation) and teleological (criteria of ends and consequences). The strength of this procedural approach in ethics is that it provides a dialogical grounding of the moral rules, as opposed to the supposedly monological one in Kant. It then links up the individual and the community's will, without supporting any particular, substantial statement on the content of the moral rule or the ethical end.

It has to be remembered that dialogism in practical philosophy, including ethics and politics, functions as a powerful influential framework and can be termed the 'dialogical revolution'. Thus, the dialogical paradigm gathers a great variety of authors and streams, forming an impressive set of dialogical sub-paradigms or models. This is obvious within the contemporary philosophy rooted in the 'Aristotelian' triptych (logic, dialectic and rhetoric). One can mention, for instance, the 'dialogical logic' of Lorenzen and Mackenzie, ${ }^{21}$ the 'new rhetoric'

21 See for example: JD Mackenzie, 'The dialectics of logic', Logique et Analyse n.s., vol 24, 1981, pp 159-77; or P Lorenzen and K Lorenz Dialogische Logik. 1978, Wissenschaftliche Buchgesellschaft: Darmstadt. 
of Perelman ${ }^{22}$ or the 'new dialectics' of Van Eemeren and Grootendorst. ${ }^{23}$ This is also the case in contemporary philosophy and human sciences, including linguistics, psychology, sociology, or anthropology. One can mention the critical rationalism of Popper, the phenomenology of communication of Lanigan, the polyphony of Bakhtin, the anthropology of communication of Winkin, the dialogical sociology of technology in Callon and Latour. ${ }^{24}$

It happens that some streams and authors, which are critical towards the dialogical paradigm, such as the current researches of Axel Honneth elaborating on the notion of struggle for recognition, are refinements of the Habermassian model grounded on the activity of communication (1996). Some others like Pierre Bourdieu (1997), for instance, who is certainly, with Rorty, one of the most critical authors of Habermas, also advocates for an ideal of free social communication. This norm for dialogical situations, which is quite different in the method of discussion from the ideal speech situation, is, surprisingly enough, close to that of Habermas. Today, it is difficult to develop theoretical and conceptual investigations as well as practical and experimental implementations in ethics without referring to the dialogical paradigm and, further, to the procedural approach. Dialogical proceduralism has become to some extent the ideological grounding of the social exchange in general and of the discursive exchange in particular.

Yet, dialogical procedures, while being a means to avoid the pitfalls of both deontological and teleological theories, face, at least on some crucial points, the same kind of limit. The major limit is that of the context and, more precisely, the relationship between the rational justification of norms and the context of application of norms. Dialogical procedures cannot avoid criticism of the limited relevance of norms to the context, and so their supporters claim for the moral norms to be regarded as universal rules or, at least, universalisable ones. The problem is that the procedure of discussion within a community, even an informed community like a parliament, for instance, is not sufficient to warrant the relevance of the norm to a wider community, who is supposed to apply this norm within the proper life form. There must be something more than a mere procedural discussion to elaborate a rational justification of a norm and almost simultaneously adapt it to the specificity of a social and cultural context. ${ }^{25}$

\footnotetext{
22 See for example : Chaïm Perelman and L Olbrechts-Tyteca, The new rhetoric: A treatise on argumentation, University of Notre Dame Press, 1991.

23 See F Van Eemeren and R Grootendorst, A systematic theory of argumentation, the pragma-dialectical approach, Cambridge University Press, 2004.

24 M Callon and B Latour, 'Unscrewing the big Leviathan: How actors macro-structure reality and how sociologists help them to do so', in K Knorr-Cetina \& AV Cicourel (eds), Advances in social theory and methodology: Towards an integration of micro- and macro-sociologies, Boston: Routledge \& Kegan Paul, 1981, pp 277-303.

25 S Lavelle, contribution to the EGAIS deliverable - P Goujon, C Flick, ‘Deliverable 2.1 grid-based questionnaire development'.
} 
In order to address this contextual blindness, we will criticise the procedural reason behind it. An ethical norm needs to be conceived with a feedback mechanism that is induced by the anticipation of the norm's insertion into the coherence of an application field. It must be questioned, from its point of view, about its capacity to participate in the emergence of a way of life. If we take the conditions seriously, all such Kantian schema approaches are fundamentally insufficient because they are still dominated by a logic of subsumption (deductive relation). The context itself refers the norm to its effective possibilities, confronting it with all of the possibilities in which it can be accommodated within the world. This fundamental and radical epistemological reversal is contained by all normative elaborations and, by itself, allows the norm to be translated in effective power in a given context. This is because the normative elaboration process integrates the reflexivity on the conditions that ensure the effective expression of the norm from the beginning.

A governance process, therefore, is needed that integrates 'learning' through the process of development and broadens the view beyond the technical, opening questions and debate regarding values. To do this we need to address the question of the conditions required for the effective insertion of an ethical norm into a context, from the very beginning.

To be able to confront these practices with this question, we need to understand the limitations of actual ethical and theoretical trends, in particular the limitations of proceduralism.

\section{Limitations of proceduralism}

Proceduralism (particularly that of Habermas, 1981) holds that a normative statement's semantic content is not important, but the approval process by concerned parties is the validating step. Thus, free approval needs to be gained for a normative statement to be considered valid. In exploring the limitations of proceduralism we rely on the analysis of Lenoble and Maesschalck (2003) in their book Toward a theory of governance: the action of norms.

Proceduralism seems to solve the problems outlined above because it proposes an internalist, rather than externalist, point of view. The current Habermasian (1981) approach takes into account the reversibility of the operation of justification and the application of rules. This dimension of reversibility indicates a codependence between these two operations, that is, that the application of the rule act retrospectively upon its justification. Therefore, the choice of a relevant norm necessitates a reflexive return on its context of application. This, however, leads to a supposition that the elements which condition the application of the rule are subsumable under rules that guide formal discursivity of the mechanism which is mobilised by the formal calculation of the relevant rule. Procedural 
relations, however, can resolve situations where two conventions of relations to the norm come into conflict, which is not a situation that can be resolved with the conventional relation. Every judgement, and thus every norm, since a norm is the result of a judgement, can only be applied at the end of an operation. The operation is an exchange between the effects expected by the abstract norm and the possible effects raised by the coherences specific to the existing way of life; that is, we encounter the difficulty of actually expressing abstract norms in reality: that it does not necessarily invoke the effects expected, and the effects that are realised are quite specific to the context in which the expression takes place.

The norm can thus only be inscribed in reality, and can only make sense by being supported by particular perceptions of the way of life, and particularly those whom the rule affects. It fails to allow for any reflexive capacity for the actors to identify the various effective possibilities on which the operation of the selection of the relevant norm will be carried out. There is also an implicit limitation of this approach, which is that the discursive and rational construction of the definition of the relevant norm is capable by itself to take into account all possibilities of the social context to be regulated. Although there is a reflexive approach to rationality, there is no reflexivity relating to the context.

Although this does not invalidate the discursive procedure for reasoned elaboration of relevant rules, it does require that the arrangements for normative production be more complex. The choice of a relevant rule consists of a making a decision about a real-life solution that is supposed to optimise the ideal objective drawn out by the anticipation of an idealised way of life. The choice of this solution, however, rests precisely on an operation of the selection of possibilities that does not exhaust the possibilities of the context within which the idealised way of life would have been realised. Transforming the context with the view to incorporating an ideal norm within it will only result from operations of interpretation that cannot be formalised. Nothing within the formal mechanism can guarantee that the choice of possibilities taken into account in order to define the choice of a norm will ensure that the realisation of this ideal will correspond to any one of the diverse possibilities perceived by the actors concerned. It is therefore necessary for a rational procedure of the calculation of norms to be intersected by reflexive incentives. This would allow for the reconstruction of the problems that condition peoples' practical acceptance of the transformation of their way of life. Without this prior reflexive effort, the processes that would enable the effective expression of relevant norms would probably not be taken into account.

The operation of the selection of possibilities carried out by the production of each norm cannot therefore be restricted by the rules, because of the guarantee of the discursive operation of formal reason. The effective possibilities drawn 
out by the social application of a norm are a function of the conditionality that depends on the structure of the context. These can only be reconstructed within a concrete act of community reflexivity whose conditions are not anticipated by the formal rules of the discursive act.

Using the Louvainist contextual pragmatic theory (Lenoble \& Maesschalck, 2003; 2006) we can underline the limitations of every theory that presupposes the conditions that makes the exercise of reason possible. This is true for all the theoretical ethical approaches that are characterised, according to Lenoble and Maesschalck's terms, as 'intentionalist, mentalist, and schematising' presuppositions.$^{26}$ Even if individuals are able to revise or adapt these conditions, they do not take into account the reversible or reflexive character that allows for these revisions or adaptations.

The criticism we level here emphasises the necessity of understanding the reference to the background as a speculative and transcendental logical constraint of the operation. This allows us to better understand the consequence of our approach to the reflexivity of judgement on the level of the construction of governance arrangements.

\section{Theoretical consequences for an ethical governance}

As Lenoble and Maesschalck point out in Toward a theory of governance (2003, 91-3) 'Every norm aims to institute a way of life that is judged to be rationally more acceptable' ${ }^{27}$ The formal rules that condition the rationality of this choice, such as calculation of optimisation, argumentative rules, or any formal mechanism, don't guarantee, by themselves, the transformation of existing ways of life. The realisation of the ideal way of life that is called for by the norm is conditioned by something other than the simple formal validity of the rule.

The norm can only be expressed in reality by establishing a reflexivity on the perceptions of the ways of life that are lived by and accepted by those to whom the norm is addressed. To suppose that the adaptation of the dominant

\footnotetext{
26 The 'intentionalist' presupposition is so named because the norm's effects are supposed to be deducible from the simple intention directing its adoption; and the 'mentalist' and 'schematising' presuppositions are so named because what enables the determination of the effect of a norm is supposed to be linked to the rules (or schemes, in Kant's language) located in every mind. In this presupposition, there is a function of mental capacities, therefore, that do not at all depend on a thinking subject's exterior context. The operation of application can be considered, in this case, as a simple formal operation of deduction on the basis of the rule itself.

27 The following background and justification for a reflexive approach is largely based on the large amount of work done on this subject by Lenoble and Maesschalck in the Centre de Philosophie du Droit (CPDR), at the University of Louvain.
} 
perception and the corresponding actions in reality will happen automatically or can be directly linked to the simple implementation of a formal mechanism conditioning the social acceptability of the norm is misunderstanding this reflexivity.

The insufficiency of proceduralism, as explained previously, is evident in that the arrangements that are necessary for organising the reflexive capacity for the actors to identify the various effective possibilities on which the operation of the selection of the norm will be carried out are problematic. Whether a norm is effective in modifying a way of life in a rationally acceptable way presupposes an independence from the discursive procedures that are used to select what is rationally acceptable. That is, all the procedural mechanisms and rational approaches to the determination of a norm cannot by themselves assure the modification of the way of life.

If we were to increase the capacities for reflexivity with regard to the conditions for the production of the norm, the effectiveness of norm expression could be measured according to the incentives required to enable the reflexive reconstruction by the actors, driven by what motivates their institution of a new way of life.

Without the organisation of a common reflexive capacity, and the form of negotiation it involves between the norms to be constructed, the normative injunction risks remaining ineffective, even if the objective is judged relevant and legitimate. The operation of judging the conditions of the choice of the rationally acceptable idealised way of life, that is, the rational determination of the norm that is supposed to enable the realisation of this objective, and the effective transformation of this way of life by the application of the norm, is distinct and asymmetric. Asymmetry is the way in which the social meanings of a norm are conditioned by an operation that cannot be anticipated by formal variables of reasoning (variables that condition the norm's relevance). Therefore every reconstruction of the process that was enacted by the production of a norm itself mobilises two operations, which do not respond to the same conditions of production. The intersecting articulation of this asymmetry is the focus for governance arrangements.

In order to do this, it is necessary to organise the reflexive capacity of the actors by constructing the capacities of the reflexivity in such a way as to not presuppose it as already existing due to a formal method, such as argumentation, deliberation, debate or discussion. All of these formal methods presuppose their own required conditions and, as such, do not necessarily involve reflexivity. It is therefore important to make sure that every application of a norm presupposes 
not only a formal moment of choice of its acceptable normative constraints, but an operation of the selection of the possibilities according to the acceptable way of life within the community concerned.

Without a negotiated construction of the moment of reflexivity that is specific to the conditions for the application of the norm, however, there will be no control of the process of the expression of the norm, and it will be left to the dominant common culture to express. Thus, what is often presented as the only effective choice is always conditioned by an operation such as the above (including in the construction of the deontological codes). Criticism of this reconstruction of the reflexivity used in the construction of the social norm also affects the moral approaches to legitimacy. Economic theories often obliterate the operation of the choice of possibilities that already condition the effects of rational decisions, ${ }^{28}$ but the deliberative or communicative approaches also miss the question of the conditions for an effective expression of the ethical objectives they intend to promote.

Institutional cooperative arrangements are necessary for the effectiveness of the expression of norms in concrete situations, as well as for the legitimisation process for the norm. These arrangements result from the contextual limitation as an inescapable part of the reflexive operator of modality.

According to our analysis, what is needed is a profound change in the "modes of inquiry' (Stiglitz 2002, 244; Bohman 2004, 347) that respect the requirement of the fact that the context has to be constructed in the ethical analysis respecting its complexity and secondly respect the ethical normativity characteristic.

\section{Conclusion}

In this chapter, we have argued that the current methods for approaching ethics in technical and scientific projects are insufficient because they lack a thorough mechanism for implementing ethical change within these projects due to a separation between technology and ethics, that is, that they are highly formalist approaches.

To take into account these limitations and achieve second-order reflexivity, we need to escape the binds of formalism, which constrains ethics with its presuppositions, that is, that the determination of ethical issues provides a method for resolution of these ethical issues, and internal limitations. To more effectively incorporate ethical norms into contexts, it is necessary to construct the framing of the context in relation to the norm (ie not presuppose it), then 
open up this context so that we can have a reflexivity on the opening of this framing (that is, a feedback mechanism). In order to do this, there is a need to reconstruct, from a normative perspective, how research projects should reconstruct the two-way relationship between the norm and the context to overcome the fundamental limitations outlined above in order to achieve a second-order reflexivity, an issue that will be addressed by the EGAIS project and by the authors of this chapter.

\section{References}

Bauman, Z, 1995, Life in fragments: essays in postmodern morality, Blackwell Publishers, Oxford.

Barker, JR, 1993, Tightening the iron cage: concertive control in self-managing teams, Administrative Science.

Bohman, James, 'Realizing deliberative democracy as a mode of inquiry: Pragmatism, social facts, and normative theory, The Journal of Speculative Philosophy, vol 18, no 1, pp 23-43.

Bourdieu, P, 1997, Méditations pascaliennes, Seuil, Paris.

Callon, M \& Latour, B, 1981, Unscrewing the big Leviathan: how actors macrostructure reality and how sociologists help them to do so, in K Knorr-Cetina \& AV Cicourel (eds), Advances in social theory and methodology: Towards an integration of micro- and macro-sociologies, Boston: Routledge \& Kegan Paul, pp 277-303.

Cetron Marvin J, Connor Lawrence W, 1972, 'A method for planning and assessing technology against relevant national goals in developing countries', in Marvin J Cetron, Bodo Bartocha, The methodology of technology assessment, Gordon and Breach Science Publishers, New York.

Coppens, P \& Lenoble, J, 2000, Démocratie et Procéduralisation du Droit, Bruylant, Bruxelles.

Crutzen, Cecile KM, 2003, 'ICT-representations as transformative critical rooms', in Gabriele Kreutzner \& Heidi Schelhowe (eds) Agents of change: Virtuality, gender, and the challenge to the traditional university, Leske Budrich: Opladen, pp 87-106.

Joseph F Coates, 1995, 'Technology assessment: Here today, gone tomorrow, in Technological Forecasting \& Social Change, 49, pp 321-23. 
Drenth, PJD , Honnefelder, L, Schroots, JJF \& Sitter-Liver, B (eds), 2006, In search of common values in the European research area, ALLEA, Netherlands.

European Commission (EC) (2002), Science and society: action plan, European Commission, Brussels.

Friedman, Batya, Kahn, Jr, Peter H, \& Borning, Alan, 2006, Human-computer interaction and management information systems: Foundations. ME Sharpe.

Gadamer, HG, 1976, Philosophical hermeneutics, ed and trans by DE Linge, University of California Press, Berkeley.

Gentil, E, 1997, Penser la modernité, Essai sur Heidegger, Habermas et Eric Weil, Presse Universitaire de Namur.

Habermas, J, 1981, Theory of communicative action.

—_, 1992, De l'éthique de la discussion, Passages, Cerf.

_ 1997, Droit et démocratie, entre faits et normes, Galimard.

Honneth, A, 1996, Struggle for recognition. The moral grammar of social conflicts, Polity Press.

Isaac, H, \& Kalika, M, 2001, 'Organisation, nouvelles technologie et vie privée', Revue Française de gestion, Juillet- Aout, pp 101-06.

Ladrière, J, 1993, 'Les incertitude's de la conscience historique', Cahier de l'école des sciences philosophiques et religieuses.

Ladrière, J \& Van Parijs, Ph, 1984, Fondements d'une théorie de la justice. Essais critiques sur la philosophie politique de John Rawls, Éditions de l'Institut Supérieur de Philosophie, Louvain-la-Neuve.

Lenoble, J \& Maesschalck, M, 2003, Toward a theory of governance: the action of norms, Kluwer Law International.

- 2006, Beyond neo-institutionalist and pragmatic approaches to governance, REFGOV, FP6

Lorenzen, P and Lorenz, K, 1978, Dialogische Logik. Wissenschaftliche Buchgesellschaft: Darmstadt.

Lyon, D, 1993, 'An electronic panopticon? A sociological critique of surveillance theory', Sociological review, vol 41, no 4, pp 653-78.

Mackenzie, JD, 1981, 'The dialectics of logic' Logique et Analyse n.s., vol 24, pp 159-77. 
— 2006, Theorizing surveillance: the panopticon and beyond, Willan Publishing.

Maesschalck, M, 1998, Habitus et lien social, authors' translation.

- 2001, Normes et Contextes, OLMS.

Orlikowski, WJ, 1991, 'Integrated information environment or matrix of control? The contradictory implications of information technology', Accounting Management and Information Technology, vol 1, no 1, pp 9-11.

Perelman C \& Olbrechts-Tyteca L, 1991, The new rhetoric: a treatise on argumentation, University of Notre Dame Press.

Punie, Yves, 2003, A social and technological view of ambient intelligence in everyday life: what bends the trend? IPTS EMTEL2 key deliverable Work Package 2 EU FP5 HPRN-CT-2000-00063, September, Technical Report EUR 20975 EN.

Ramberg, B \& Gjesdal, K, 2005, 'Hermeneutics', Stanford encyclopedia of philosophy.

Rawls, J, 1971, A theory of justice, Harvard University Press, Cambridge (Mass).

Ricœur, P, 1990, Soi-même comme un autre, Le Seuil, Paris.

Schütz, A, 1951, 'Choosing among projects of action', Philosophy and Phenomenological Research, vol 12, pp 161-84.

- 1954, 'Concept and theory formation in the social sciences', Journal of Philosophy, 51, pp 257-72.

- 1959, 'Type and eidos in Husserl's late philosophy', Philosophy and Phenomenological Research, vol 20, pp 147-65.

Stiglitz, Jospeh, 2002, Globalization and its discontents, London: Penguin Books.

Teubner, G, 1995, Droit et réflexivité, ed. juridiques Kleuver.

van den Hoven, J, 2007, 'ICT and value sensitive design', in Ph Goujon et al (eds), The information society: innovation, legitimacy, ethics and democracy, Sprinter, p 68.

Van Eemeren, F, Grootendorst R, 2004, A systematic theory of argumentation, the pragma-dialectical approach, Cambridge University Press. 